\title{
11. COLEGIOS Y ORGANIZACIONES PROFESIONALES
}

\author{
JUAN ANDRÉS MUÑOZ ARNAU \\ Profesor Titular de Derecho Constitucional \\ Universidad de La Rioja
}




\section{SUMARIO}

I. Propuesta de reforma.-II. Justificación de la Reforma propuesTA.-1. Una cuestión previa: la propiedad en el uso de los términos. 2. Reserva de ley y competencia estatal. 3 Sobre un posible contenido esencial de las profesiones tituladas. 4. Los Colegios Profesionales desde la perspectiva de un Estado Social y Democrático de Derecho. a) El interés público -el servicio al común- como razón democrática de los Colegios. b) Los Colegios como instrumento para hacer efectiva la libertad profesional. c) Colegios y representación: la razón técnica como complemento de la razón ideológica. d) Limitación del número de profesiones colegiadas a las imprescindibles para salvaguardar el interés público. e) Posibilidad de la existencia de Colegios sin colegiación obligatoria. 


\title{
11. COLEGIOS Y ORGANIZACIONES PROFESIONALES
}

\author{
POR \\ JUAN ANDRÉS MUÑOZ ARNAU \\ Profesor Titular de Derecho Constitucional \\ Universidad de La Rioja
}

I. PROPUESTA DE REFORMA

Se propone la supresión de los artículos 36 y 52 de la Constitución y la integración de sus contenidos, convenientemente adaptados, en los artículos $7,35.1,131.2$ y 149.1.18.a ${ }^{a}$ que quedarian redactados en los términos siguientes:

\section{Artículo 7}

Los sindicatos de trabajadores y las asociaciones profesionales y empresariales, cuya creación y actividad son libres dentro del respeto a la Constitución y la Ley, y los colegios profesionales, contribuyen al interés general mediante la defensa y promoción de los intereses que les son propios. Su estructura interna y funcionamiento deberán ser democráticos.

\section{Artículo 35.1}

Todos los españoles tienen el deber de trabajar y el derecho al trabajo; a la libre elección de oficio o profesión que, en el caso de ser titulada, se regulará por ley; a la promoción a través del tra- 
bajo y a una remuneración suficiente para satisfacer sus necesidades y las de su familia, sin que en ningún caso pueda hacerse discriminación por razón de sexo.

\section{Artículo 131.2}

El Gobierno elaborará los proyectos de planificación de acuerdo con las previsiones que le sean suministradas por las Comunidades Autónomas y el asesoramiento y colaboración de los sindicatos de trabajadores, las asociaciones profesionales y empresariales, los colegios profesionales y otras instituciones económicas. A tal fin se constituirá un Consejo, cuya composición será proporcional a la importancia numérica y cualitativa de las entidades mencionadas.

\section{Artículo 149.1.18. ${ }^{\mathrm{a}}$}

1. El Estado tiene competencia exclusiva sobre las siguientes materias:

18..$^{a} \quad$ Las bases del régimen jurídico de las Administraciones públicas y del régimen estatutario de sus funcionarios que, en todo caso, garantizarán a los administrados un tratamiento común ante ellas; la regulación del régimen jurídico de los Colegios Profesionales en sus aspectos básicos; el procedimiento administrativo común, sin perjuicio de las especialidades derivadas de la organización propia de las Comunidades Autónomas; legislación sobre expropiación forzosa; legislación básica sobre contratos y concesiones administrativas y el sistema de responsabilidad de todas las Administraciones publicas. 


\section{JUSTIFICACIÓN DE LA REFORMA PROPUESTA}

La mención que el texto constitucional hace de los Colegios Profesionales (art. 36) y de las organizaciones profesionales (art. 52) aunque con expresiones distintas de las empleadas para referirse a los sindicatos de trabajadores y a las asociaciones empresariales (art. 7) no puede responder a intenciones diferentes.

En mi opinión, unos textos y otros, reflejan la voluntad de una participación de los grupos de interés en los procesos sociales como una exigencia derivada del Estado social y democrático de Derecho proclamado por la Constitución (art. 1).

El que la importancia de cada uno de esos grupos de interés sea desigual en orden a la configuración de la vida social, política y económica del Estado no justifica su ubicación en lugares distintos del Titulo Preliminar donde figuran los sindicatos y las asociaciones empresariales.

El art. 7 es, a mi parecer, el más adecuado para referirse a ellos. No sin razón, el Dictamen del Pleno del Congreso (B.O.C. de 24 de julio de 1978) ofrecía una redacción parecida a la que propongo, con alguna diferencia significativa.

Lo que resulta indudable es lo inadecuado de la referencia a los Colegios Profesionales en la Sección Segunda del Capítulo II del Título I que se ocupa de los derechos y deberes de los ciudadanos, y la inclusión de las organizaciones profesionales en el Capítulo III del mismo Título, dedicado a los principios rectores de la política social y económica.

Pero ambos artículos no planean únicamente problemas de sistemática. Yo diría que la nueva incorporación al texto constitucional de los Colegios y de las organizaciones profesionales -en expresión de la Constitución- exige un proceso previo de depuración desde el punto de vista de la técnica constitucional.

\section{Una cuestión previa: la propiedad en el uso de los términos}

El art. 7 de la C.E. se refiere a las asociaciones empresariales; sin embargo, al art. 131.2 habla de organizaciones empresariales ¿Son unas $y$ otras, realidades diferentes? ¿Utilizó el constituyente las expresiones asociaciones $y$ organizaciones como sinónimas? 
La cuestión tiene su importancia. Si se confirmara la primera hipótesis, quizás, lo que el constituyente quiso en el art. 7 fue señalar a los principales protagonistas espontáneos de la vida social, las fuerzas sociales nacidas del ejercicio de un derecho de asociación en unas manifestaciones privilegiadas; la idea de participación estaría en la base de la mención indicada. En este caso, el art. 131.2, más atento a un problema de representación - hay que tener en cuenta que la enumeración de agentes sociales se hace en vista del establecimiento futuro de un Consejoquerría referirse, en el caso de las organizaciones profesionales y empresariales a los órganos de conjunción, coordinación, gobierno y representación de unas asociaciones que sí serían expresión del dinamismo social. Aun con todo, esta perspectiva no es del todo halagüeña, sobre todo si se lee este artículo a la vista de art. 52 que establece: "la ley regulará las organizaciones profesionales que contribuyan a la defensa de los intereses económicos que les sean propios". Esta expresión refleja un exorbitante intervencionismo estatal en la vida social: legitimaría la regulación por ley de esos posibles órganos de conjunción, coordinación, gobierno y representación de los profesionales estableciéndose una diferenciación, a mi juicio no justificada, en relación con las organizaciones empresariales.

Si se confirmara la segunda hipótesis, es decir, la ligereza en el uso de palabras distintas para designar una misma realidad, al equiparar organizaciones y asociaciones el art. 52 se convertiría en dudosamente constitucional ya que tendría esta lectura: "la ley regulará las asociaciones profesionales que contribuyan a la defensa de los intereses económicos que les sean propios".

El Tribunal Constitucional, aunque no con la contundencia necesaria, señalaba en las Sentencias 67/85 de 24 de mayo y 132/89 de 18 de julio, entre otras que podrían aducirse, el peligro de esa transformación estatalizante de la espontaneidad social.

¿Por qué habría de reconocerse la libre creación de organizaciones empresariales, cuya actividad se proclama también libre, y regular, sin embargo, por ley, las organizaciones profesionales? Parece razonable establecer el mismo régimen para unas y otras y situarlas en el mismo artículo aun reconociendo su desigual relevancia social, y utilizar además, en todos los casos, los mismos términos para designarlas: asociaciones. 


\section{Reserva de ley y competencia estatal}

El art. 36 y el art. 52 establecen sendas reservas de ley en favor de la regulación de los Colegios y de las organizaciones profesionales a las que se añade la referente a la disciplina del ejercicio de las profesiones tituladas en el primero de los artículos citados.

En mi opinión la referencia a la regulación de las profesiones tituladas debe hacerse en el art. 35.1 por las razones que se expondrán en apartado 3 .

En relación con los Colegios Profesionales, la regulación de las peculiaridades propias de su régimen jurídico, como competencia estatal debe figurar expresamente en el art. 149.1.18 ${ }^{\mathrm{a}}$. El Tribunal Constitucional en sentencias recaídas en un recurso de inconstitucionalidad (S.T.C. 20/88 de 18 de febrero) y en un conflicto positivo de competencias (S.T.C. $87 / 89$ de 11 de mayo) respectivamente, repite una argumentación anterior (S.T.C. 76/83) según la cual, correspondería al Estado en virtud del art. 149.1.18. ${ }^{a}$ "fijar los principios y reglas básicas a que han de ajustarse su organización y competencias las Corporaciones de Derecho Público representativas de intereses profesionales". Creo que la afirmación de nuestro Tribunal Constitucional no se ajusta a la realidad de los Colegios Profesionales que, aunque tengan la consideración de Corporaciones de Derecho Público, no son Administración Pública. Por lo tanto, en su redacción actual, el artículo de referencia no permite la interpretación formulada por el Tribunal.

\section{Sobre un posible contenido esencial de las profesiones tituladas}

Estaría justificada la posibilidad de incluir la regulación del ejercicio de las profesiones tituladas en el art. 149.1.7, y quedaria redactado así: "Legislación laboral y ejercicio de las profesiones tituladas, sin perjuicio de su ejecución por los órganos de las Comunidades Autónomas". Sin embargo también parece fundado incluir esas referencia en el art. 35.1 si se considera que puede existir un contenido esencial en las profesiones tituladas aunque el Tribunal Constitucional afirma que la reserva de ley del art. 36.1 es específica y distinta de la general que se contiene en el art. 53.1 y que, por consiguiente, "la regulación de las distintas profesiones, oficios o actividades empresariales en concreto, no es por tanto una regulación del ejercicio de los derechos constitucionalmente garantizados en los artículos 35.1 ó 38» (S.T.C. $83 / 84$ de 24 de julio, f.j. 3). 


\title{
4. Los Colegios Profesionales desde la perspectiva de un Estado Social y Democrático de derecho
}

\begin{abstract}
"Cierto es que la C.E. (...) si bien constitucionaliza la existencia de los Colegios Profesionales, no predetermina su naturaleza jurídica, ni se pronuncia al respecto, pero hay que convenir que con su referencia a las peculiaridades de aquéllos y a la reserva de ley, remitiendo a ésta su regulación (art. 36), viene a consagrar su especialidad - "peculiaridad"ya reconocida, de otro lado por la legislación citada" (S.T.C. 89/89 de 11 de mayo, f.j. 5).
\end{abstract}

El texto citado, parte del fundamento jurídico 5 que continúa con un razonamiento de extrema importancia al señalar al legislador la forma en que debería establecerse su regulación para adaptarse a las exigencias constitucionales, explica muy bien el porqué de las reservas que prestigiosos constitucionalistas formulan al precepto en cuestión.

Es verdad que se anuncia una futura ley de Colegios, pero existe ya la del $2 / 74$ de 13 de febrero modificada por la ley $74 / 78$ de 26 de diciembre que es el punto de referencia desde el que se razona. La indicación de unas peculiaridades por venir se intuyen desde unas peculiaridades presentes que condicionan su entendimiento.

A mi juicio, es desde la Constitución presente, desde los derechos, bienes y valores constitucionalmente proclamados, como se ha de encarar el problema que plantean los Colegios a la propia Constitución.

Me atrevo a sugerir algunas posibles vías para esa "nueva" incorporación de los Colegios al texto constitucional como cauces válidos de participación, algunos de ellos abiertos por la ley vigente y la propia jurisprudencia constitucional.

a) El interés público —el servicio al común-como razón democrática de los Colegios.

La Constitución española utiliza frecuentemente la expresión «estructura y funcionamiento democráticon. Sin embargo deberiamos pensar en la democracia como otra cosa, aunque esa otra cosa no pueda llegar a serlo sin esas exigencia formales. Me refiero al carácter instrumental de la "estructura y la función" en relación con el mantenimiento de una profesión que muchas veces estará destinada a preservar derechos de los ciu- 
dadanos o bienes y valores constitucionalmente protegidos: los Colegios deben servir ante todo, para la defensa de una profesión entendida como servicio al común cuya actividad como resultado es materia de derechos para los ciudadanos. Por eso es acertado que las decisiones de los órganos de gobierno de los Colegios tengan la consideración de actos de poderes públicos a los efectos del recurso de amparo.

b) Los Colegios como instrumentos para hacer efectiva la libertad profesional.

La existencia de los Colegios no se entiende si no es con referencia al contenido del art. 35, cuando proceda; es decir, como instrumento para hacer efectiva la libertad profesional. En este aspecto, el Colegio debe erigirse en instrumento de defensa de los colegiados frente a posibles extralimitaciones de los poderes públicos.

c) Colegios y representación: la razón técnica como complemento de la razón ideológica.

La futura ley debería facilitar de manera eficaz la participación de los Colegios de manera más o menos estable en la adopción de decisiones en que perspectiva técnica se presenta como una exigencia que se impone a las razones ideológicas.

d) Limitación del número de profesiones colegiadas a las imprescindibles para salvaguardar el interés público.

En este sentido los derechos de los ciudadanos y los bienes y valores constitucionalmente protegidos podrían erigirse en criterios para determinar en qué medida está fundada la creación del Colegio correspondiente.

e) Posibilidad de la existencia de Colegios sin colegiación obligatoria.

Aunque la jurisprudencia del Tribunal Constitucional ha declarado conforme a la Constitución la colegiación obligatoria, no obstante el dere- 
cho negativo de asociación, por entender que existen razones que lo justifican y que, por otra parte, aquélla es compatible con los derechos de asociación y sindicación, se podría pensar, partiendo de la situación actual, en la existencia de los Colegios entendidos como meros cauces privilegiados de participación en funciones públicas del que estarian privados los profesionales que voluntariamente no quisieran integrarse en los Colegios. Siempre conservarian el derecho que el art. 105 de la Constitución española reconoce a los ciudadanos directamente o a través de las organizaciones $y$ asociaciones reconocidas por la ley en orden a participar en la elaboración de las disposiciones administrativas que les afectasen.

Desde la perspectiva de los ciudadanos este planteamiento se traduciría en un mayor riesgo - que podrían asumir libremente- frente a actuaciones inconvenientes de los profesionales ante las cuales sólo tendrian la defensa civil y penal; sin la ventaja que supone la vía administrativa y contenciosa y el eventual recurso al amparo constitucional. Siempre contarian, por otra parte, con la garantía que ofrece la regulación por ley, del ejercicio de las profesiones tituladas. 